\title{
Severity of the Rheumatoid Arthritis in Sub-Saharan Africa: Study of 403 Senegalese Observations
}

\author{
Moustapha Niasse1, Baïdy Sy Kane², Abdoul Aziz Ndiaye³ ${ }^{3}$ Awa Cheikh Ndao², Boundia Djiba², \\ Seynabou Fall ${ }^{4}$, Ngoné Diaba Diack ${ }^{5}$, Fatimata Bintou Sall6, Michel Assane Ndour5, \\ Nafy Diagne ${ }^{2}$, Atoumane Faye ${ }^{2}$, Biram Codou Fall' ${ }^{5}$, Souhaïbou Ndongo ${ }^{2}$, Abdoulaye Pouye ${ }^{2}$ \\ ${ }^{1}$ Department of Rheumatology, Center Hospital Aristide Le Dantec, Dakar, Senegal \\ ${ }^{2}$ Department of Internal Medicine, Center Hospital Aristide Le Dantec, Dakar, Senegal \\ ${ }^{3}$ University of Bambey, Bambey, Senegal \\ ${ }^{4}$ Department of Hematology, Center Hospital DalalJamm, Dakar, Senegal \\ ${ }^{5}$ Department of Internal Medicine/Endocrinology, National Pikine Hospital Center, Dakar, Senegal \\ ${ }^{6}$ Department of Hematology, Center Hospital Aristide Le Dantec, Dakar, Senegal \\ Email: moustaphaniasse4@yahoo.fr, baidykane@gmail.com,ndiaziz2000@yahoo.fr, awacn@voila.fr, boundiadjiba@yahoo.fr, \\ seyna.fall@gmail.com,diackngone@gmail.com, fabisall3007@gmail.com, michelassanendour@yahoo.fr, \\ diagnenafissatou@yahoo.fr, atoufayemi@yahoo.fr, biramfall86@gmail.com,sndongo_medeinterne@yahoo.fr, \\ docpouye@yahoo.fr
}

How to cite this paper: Niasse, M., Kane, B.S., Ndiaye, A.A., Ndao, A.C., Djiba, B., Fall, S., Diack, N.D., Sall, F.B., Ndour, M.A., Diagne, N., Faye, A., Fall, B.C., Ndongo, S. and Pouye, A. (2017) Severity of the Rheumatoid Arthritis in Sub-Saharan Africa: Study of 403 Senegalese Observations. Open Journal of Internal Medicine, 7, 151-159. https://doi.org/10.4236/ojim.2017.74016

Received: September 30, 2017 Accepted: November 17, 2017 Published: November 20, 2017

Copyright (c) 2017 by authors and Scientific Research Publishing Inc. This work is licensed under the Creative Commons Attribution International License (CC BY 4.0).

http://creativecommons.org/licenses/by/4.0/ (c) (i) Open Access

\begin{abstract}
Introduction: We assess the severity of the rheumatoid arthritis in a Senegalese African black population. Patients and methods: It is a retrospective study achieved in the service of Internal Medicine of Aristide Le Dantec teaching hospital of Dakar between January 2005 and December 2016 in patients suffering from rheumatoid arthritis. We specified for every patient the predictive data of severity of the rheumatoid arthritis. Results: Four hundred and three patients have been gathered ( 39 men and 364 women), with the mean age of 45.8 years. An active tobacco addiction was noticed in 10 patients. The diagnostic delay was on average of 72 months. Characteristic articular deformations were noticed in 215 patients (53.3\%). They were correlated to male ( $\mathrm{p}=0.038)$, to age $(\mathrm{p}=0.001)$ and to the activity of the rheumatoid arthritis $(\mathrm{p}=0.0445)$. Systemic manifestations have been observed in 213 cases (52.9\%), particularly anemia $(50.8 \%)$. They were correlated to the anti-CCP antibodies $(\mathrm{p}=0.047)$. The ESR was increased at the first hour in $84.4 \%$ of cases (median: $43 \mathrm{~mm}$; extreme: 1and 160). CRP was elevated in $63.71 \%$ of cases (median of $12 \mathrm{mg} / \mathrm{l}$; extreme: 1 and 384). The rheumatoid factor was positive in $57.6 \%$ of the cases. The anti-CCP antibodies were present in $89.2 \%$ of the cases. Articular erosions were objectified in all cases. A DAS 28 superior to 5.1 was noticed in $71 \%$ of
\end{abstract}


cases. Conclusion: The rheumatoid arthritis was severe in our study.

\section{Keywords}

Rheumatoid Arthritis, Africa South of the Sahara, Senegal

\section{Introduction}

The rheumatoid arthritis (RA) represents the first inflammatory chronic rheumatism in the general population [1] [2] [3]. It is clearly established, in the western literature, in particular, that the RA is a potentially severe affection from its articular after-effects and its systemic complications [2] [4]. The predictive factors of severity of the RA combine a clinic and or elevated immunological and biological activity, an affection or structural progression, a high rate of auto-antibodies (rheumatoid factor and or anti-CCP antibody) [5].

The RA would be relatively benign in sub-Saharan Africa for some authors [6] [7], whereas for others it is as severe as in the Caucasian populations [8] [9].

We assess in this study the severity of the RA at the time of diagnosis in a Senegalese population.

\section{Patient and Method}

It was a retrospective transversal study achieved in the service of Internal Medicine of the teaching hospital Aristide Le Dantec of Dakar of January 2005 and December 2016. We had included all patients followed for RA, fulfilling the ACR modified criteria (Table 1) [10]. The incomplete files that do not permit a reliable exploitation of the data have been excluded.

The informed consent of all the patients was required and for each of them we specified the data:

1) Epidemiological (age, sex, geographical origin);

2) The existence or not of an active tobacco intoxication;

Table 1. The 1987 ACR criteria and the amendments proposed by Liao et al.

\begin{tabular}{l} 
A. The 1987 ACR criteria \\
\hline 1) Morning joint stiffness $>1$ hour \\
2) Arthritis $\geq 3$ joints \\
3) Hand arthritis \\
4) Symmetric arthritis \\
5) Rheumatoid nodules \\
6) Serum rheumatoid factor positive \\
7) Typical radiological changes (erosion and/or demineralization in band) to the hands \\
$\qquad$ BCriteria modified by Liao are three in number \\
ACR + Anti-CCP Criteria (ACPA) \\
ACR Criteria without nodules + Anti-CCP (ACPA) \\
\hline
\end{tabular}


3) The diagnosis delay;

4) The clinic data: articular index, synovial membrane index, number of night awakening, morning stiffness duration, number of deformed joints, existence or not of extra-articular events;

5) The correlated factors to the articular deformations and to the extra-articular manifestations;

6) The immunological and biological data (presence or not of an inflammatory syndrome, rheumatoid factors and anti-CCP antibody);

7) The radiological data (presence of an erosive arthritis);

8) The predictive data of a severity of the illness in our study, were the following: an active tobacco intoxication, the clinic activity (the painful joint existence and or swollen), the biologic activity (elevated ESR, elevated CRP), a seropositivity to the rheumatoid factor and or to the anti-CCP antibodies, a structural affection (erosive arthritis and or occurrence of articular deformations), the presence of systemic manifestations and a strong activity of the illness appreciated by the illness activity score (DAS $28 \geq 5.1$ ) [11].

The data have been analyzed thanks to the Excel software, Epi info and SPSS. The test of $\mathrm{Chi}^{2}$ of Mantel Hanzel was used for the comparison of the groups. The $5 \%$ value was taken as statistical significance of the test with a confidence interval of $95 \%$.

\section{Results}

Four hundred three observations were gathered in 39 men (10\%) and 364 women $(90 \%)$, for a sex ratio of 0.1 . The average age was 45.8 years (extreme: 18 and 81 years). Two patients in 3 came from an urban environment. An active tobacco intoxication was noted in 10 patients (2.5\%). The diagnosis delay was 72 months (extreme: 3 and 704 months). The number of painful joints was an average of 26 (extreme: 0 and 28), that of the swollen joints 2 (extreme: 0 and 28). Seven patients in 10 showed a night wakening notion following the articular pains, with minimum 2 night wakening in 55\% among them. The duration of morning stiffness was superior to $30 \mathrm{~min}$ in $82 \%$ of cases. Characteristic joint deformations were noted in 215 patients (53.3\%) among whom, the 118 at least had 2 deformed joints. The most frequent type of articular deformation was cubital gust of wind aspect (45\% of cases). The articular deformations were correlated to male $(p=0.038)$, to age $(\mathrm{p}=0.001)$ and to the activity of the RA $(\mathrm{p}=0.0445)$. Extra articular manifestations were noticed in 213 cases (52.9\%). The most frequent extra articular manifestation was anemia (50.8\%), followed by the dry oculo-buccal syndrome as a part of a secondary Sjögren syndrome. The existence of Extra articular manifestation was correlated to the positivity of the anti-CCP antibodies ( $\mathrm{p}=0.047)$. The biologic explorations have illustrated an inflammatory syndrome with a VS in the first hour increased in 84.4\% of cases (median: $43 \mathrm{~mm}$; extreme: 1 and 160). The CRP was elevated to $63.71 \%$ of cases with a median of $12 \mathrm{mg} / \mathrm{l}$ (extreme: 1 and 384). The rheumatoid factor was positive in $57.6 \%$ of cases. The anti-CCP antibodies were 
present in $89.2 \%$ of cases.

The X-ray standard objectivized some erosive lesions to the level of the feet and or of the hands in all cases.

The RA was strongly active in $71 \%$ of cases with disease activity score (DAS 28) $>5.1$.

The predictive factors of a severity of the illness appear in the chart below and in Figure 1 and Figure 2 in Table 2.

\section{Discussion}

We conduct a study assessing the severity of the RA in an African black population of Senegalese origin. The seriousness of this affection that can be functional and vital-threatening, has been well established, particularly in the western literature [1] [12] [13]. In the African black patients, the Epidemiological and clinical presentation of the RA (female predominance, occurrence age, starting form, topography of the arthritis, articular aftereffects) is comparable to the one of the Caucasian topic [1] [7] [14] [15] [16]. However, the appreciation of the severity of the illness seems to be less elucidated [1] [6] [7] [15] [16].

So, the first west African studies on the severity of the RA, in Senegal [17], in Ivory Coast [18], in Togo [19] and in Nigeria [20], considered this illness as a rare and benign affection in black African people [21] [22]. It is thus, that a study comparing the symptomatology of the RA of two patient groups of Nigerians and British showed that the sex-ratio and the topography of the articular damage were comparable in the two groups [20]. In the Nigerian patients the RA included less articular destructions and less systemic manifestations However, [20]. The rheumatoid factor, present in $78 \%$ of the British patients has only been found in $48 \%$ of Nigerians [20]. In the recent publications in this African region, we note a rise of the impact and the seriousness of the illness, even though a lower frequency

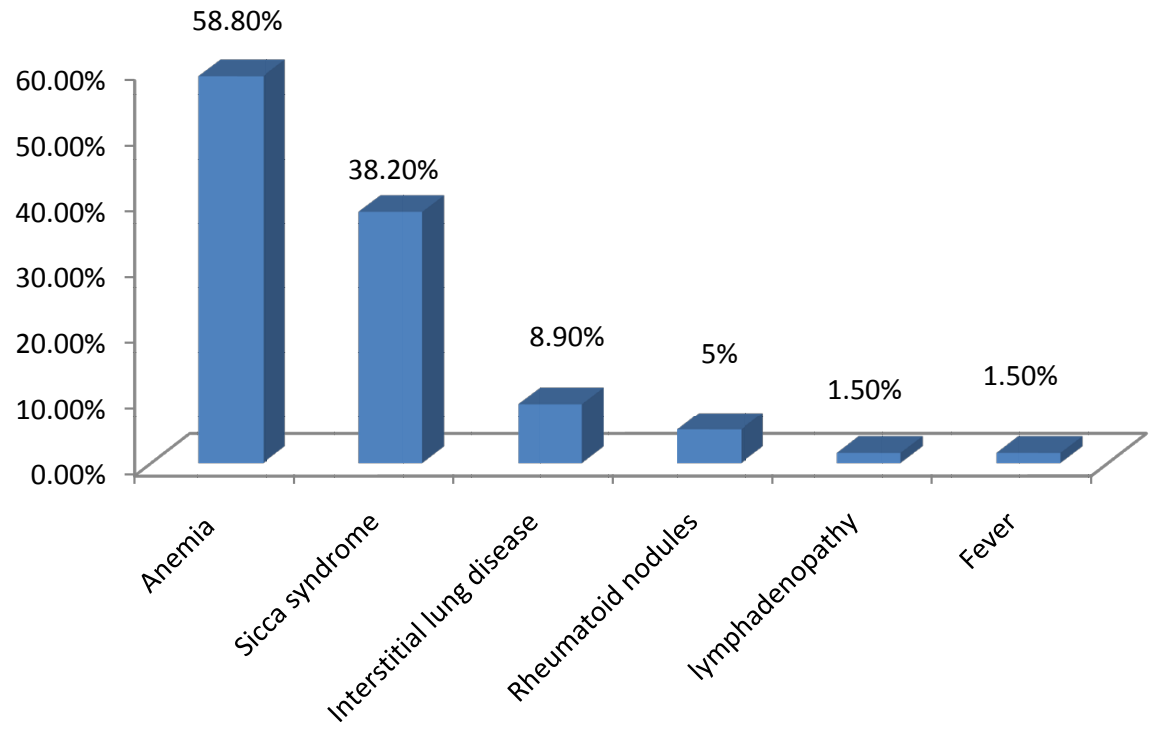

Figure 1. Description of extra-articular manifestations. 


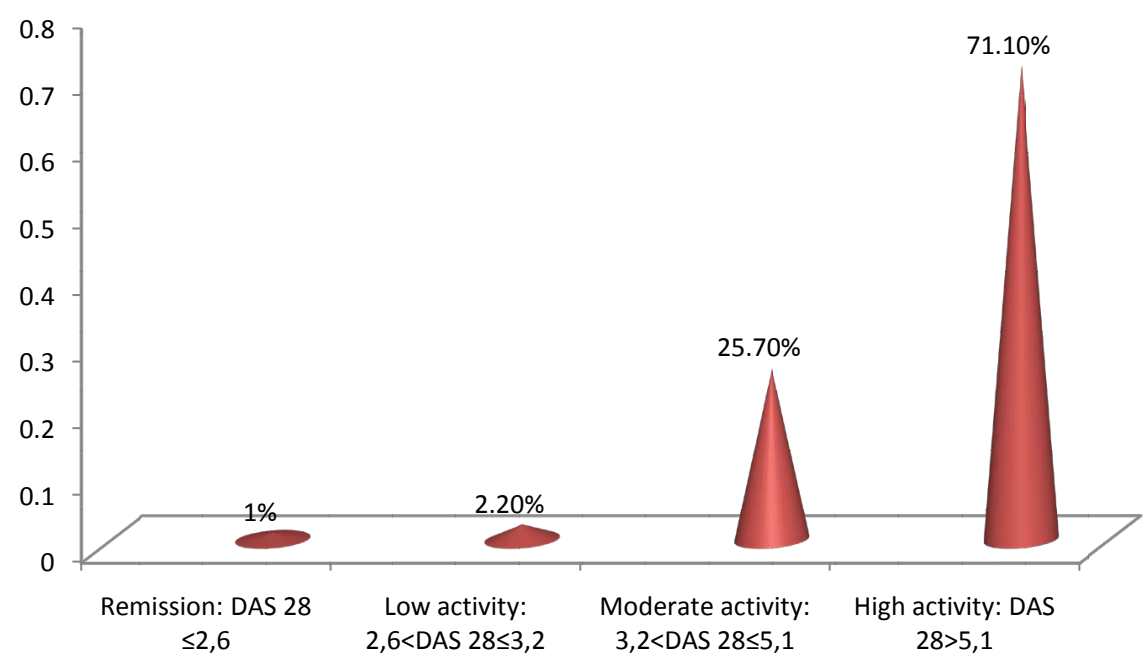

Figure 2. Description of the disease activity score.

Table 2. Description of the severity factors of RA in our patients.

\begin{tabular}{cccc}
\hline Severity factors & & Number/403 & $\%$ \\
\hline \multirow{2}{*}{ Clinical activity } & Number of painful joints: 26 (0.0; 28) & & \\
& Number of swollen joints: 2(0.0; 28) & & \\
Biological activity & increase ESR & 340 & $84.4 \%$ \\
& Increase CRP & 256 & $63.71 \%$ \\
immunological factors & RF positive & 220 & $54.5 \%$ \\
& Anti-CCP positive & 360 & $89.2 \%$ \\
structural damage & joint deformities & 215 & $53.3 \%$ \\
Extra-articular manifestations & joint erosions & 403 & $100 \%$ \\
Disease activity score & & 213 & $52.9 \%$ \\
\hline
\end{tabular}

systemic manifestation is often reported [14] [23] [24] [25] [26]. This tendency could be in relation, on one hand, to a modification of the illness or the life conditions. On the other hand, it could be merely due to a better inclusion related to a better recognition of the affection [14]. We notice in our patients a globally severe RA, proved by a score of the DAS 28 showing a strong activity of the illness (DAS $28>5.1$ in 7 patients in 10). A similar activity of the RA has also been described by other authors in West Africa [24] [25] [27]. Ndongo et al. noted a score of the DAS 28 ranging from 6.5 to 1.3 and Ouédraogo an average score of $4.79 \pm$ 1.55 [24] [25]. These data agree with those of the western literature [1].

In the French Espoir Cohort, the DAS 28 was an average of $5.1 \pm 1.32$ at the time of the inclusion of patients [1]. Dougados, et al., in a recent clinic test including the patients coming from 19 countries of Europe, America and Asia observed a base score of DAS 28 with an average of $6.4 \pm 1$ [28].

Besides the active illness, the severity of the RA in our patients was marked by an important structural damage constituted of characteristic articular deformations in 53.3\% of cases with erosions and or articular pinches in all patients. In 
the sequence of Ndongo the X-ray explorations showed some structural damages in $56 \%$ of the patients [25]. In a study assessing the structural damage in the RA in Benin Zomalhèto, et al. listed some characteristic articular deformations in 7 cases in 10 and over half of patients had a score of Larsen superior to 40 [23]. In Burkina, 9 patients in 10 presented at least a stage II of radiological Steinbrecher according to Ouédraogo et al. [24].

The strong seropositivity to the rheumatoid factor (54.5\%) and to the anti-CCP antibodies $(89.2 \%)$ noted in this study was also reported by Ndongo (rheumatoid factor: $78 \%$ and anti-CCP: 90\%) [25] and by Ouédraogo (rheumatoid factor: $70 \%$ and anti-CCP: 80\%) [24]. In the western literature we note the prevalence of the factor and superimpose able antibodies anti-CCP to these data [29] [30] [31]. In Turkey the rheumatoid factor was positive in $68 \%$ of the cases in a cohort of 526 patients enduring RA [29]. A French meta-analysis about the evolution of the RA through the time in France shows that this one is seropositive to the rheumatoid factor in $38.7 \%$ to $76 \%$ of cases [30]. In Thailand, Katchamart et al., show that the RA is combined with rheumatoid factor and with the anti-CCP antibodies, respectively in $70 \%$ and $75 \%$ of cases [31]. The strong positivity of the anti-CCP was not associated to the active tobacco addiction, in our survey.

Even though a lower frequency systemic manifestation is often reported in the west-African sequences [14] [24] [25] [26] five patients in 10 in our study presented articular extra manifestations. They were dominated by anemia (50.8\%), followed by the dry oculo-buccal syndrome as a part of a secondary Sjögren syndrome (38.2\%). In the Turkish study, the articular extra manifestations were noticed like in this sequence, in 4 patient in 10 [29], dominated however, by the rheumatoid nodules, followed by the dry syndrome [29]. A Hispanic study and Asian multicentric traces less articular extra manifestations that predominated in the Hispanic people (3 patient in 10) [32]. In brief, we can consider that the severity of the RA in the black West African people is superimpose able to the one described in the Caucasian subject.

Our results connect those of the sequence coming from other African regions [8] [27]. Solomon et al. described, thus, more than forty years ago a severity of the RA in a South African urban population comparable to the one observed in Caucasian populations [8]. The more recent studies in this region show a very active illness with a structural damage combined by an important functional reverberation, a strong seropositivity to the rheumatoid factor and to the anti-CCP antibodies [27]. This severe phenotype of RA also seems to be the case in some East African regions [9]. Elshafie et al., in comparing some Sudanese and Swedish patients suffering from RA note that the Sudanese presented the more laborious inflammatory signs, the $\mathrm{X}$-ray erosions and more severe articular deformations [9].

However, in central Africa, particularly in Congo and in the Democratic Republic of Congo the RA seems less severe [6] [7]. Malemba et al. noticed that the patients suffering from of RA, from these regions go and see the doctor late, and in spite of this late care, the majority among them didn't present major structur- 
al damage and the rheumatoid factor and the anti-CCP, are often negative [6] [7]. The same remarks have been made in Zimbabwe, where the RA had a less severe expression in rural as well as urban areas than in a Caucasian population of the Great Britain [33].

\section{Conclusion}

Our study showed a severity of the PR in our patients. It has been characterized by the strong activity of the illness, an erosive damage in all cases, by high immunological and biological markers and existence of systemic complications in 1 case in 2. This severity that is not accounted for by tobacco intoxication can be in part due to the diagnostic delay, with an average time (72 months), without excluding a genetic ground predisposing to the severity of the disease. Other studies evaluating the genetic factors in our patients are necessary.

\section{Conflict of Interest}

The authors have nothing to disclose.

\section{References}

[1] Combe, B., Benessiano, J., Berenbaum, F., Cantagrel, A. and Jean-Pierre Daurès, J.-P. (2007) The Espoir Cohort: A Ten-Year Follow-Up of Early Arthritis in France. Methodology and Baseline Characteristics of the 813 Included Patients. Revue $d u$ Rhumatisme, 74, 838-844. https://doi.org/10.1016/j.rhum.2007.06.003

[2] Bezza, A., Ghozlani, I., Rezqi, A., Achemlal, L. and Mounach, A. (2012) Diagnosis of Recent-Onset Arthritis Rheumatoid. Revue Marocaine de Rhumatologie, 19, 10-13.

[3] Mijiyawa, M., Amanga, K., Oniankitan, I., Pitch, P. and Tchangdi-Walla, K. (1999) Connective Tissue Diseases in Hospital Consultation in Lomé (Togo). La Revue de Médecine Interne, 20, 13-17. https://doi.org/10.1016/S0248-8663(99)83004-5

[4] Genta, M.S., Kardes, H. and Gabay, C. (2006) Clinical Evaluation of a Cohort of Patients with Rheumatoid Arthritis Treated with Anti-TNF-Alpha in the Community. Revue du Rhumatisme, 73, 47-52. https://doi.org/10.1016/j.rhum.2005.11.001

[5] Gaujoux-Viala, C., Gossec, L., Cantagrel, A., Dougados, M., Fautrel, B., Mariette, X., Nataf, H., Saraux, A., Trope, S. And Combe, B. (2014) Recommendations of the French Society of Rheumatology for the Management of Rheumatoid Arthritis. Revue du Rhumatisme, 81, 303-312. https://doi.org/10.1016/j.rhum.2014.04.009

[6] Malemba, J.J., Mbuyi-Muamba, J.M., Mukaya, J., Bossuyt, X., Verschueren, P. and Westhovens, R. (2012) The Epidemiology of Rheumatoid Arthritis in Kinshasa, Democratic Republic of Congo-A Population-Based Study. Rheumatology, 51, 1644-1647. https://doi.org/10.1093/rheumatology/kes092

[7] Malemba, J.J., Mbuyi-Muamba, J.M., Mukaya, J., Bossuyt, X., Emonds, M.P., Deiteren, K., Westhovens, R. and Verschueren, P. (2013) The Phenotype and Genotype of Rheumatoid Arthritis in the Democratic Republic of Congo. Arthritis Research \& Therapy, 15, R89. https://doi.org/10.1186/ar4269

[8] Solomon, L., Robin, G. and Valkenburg, H.A. (1975) Rheumatoid Arthritis in an Urban South African Negro Population. Annals of the Rheumatic Diseases, 34, 18-35. https://doi.org/10.1136/ard.34.2.128

[9] Elshafie, A.I., Elkhalifa, A.D., Elbagir, S., Aledrissy, M.I.E., Elagib, E.M. and Musa, 
A.M. (2017) Active Rheumatoid Arthritis in Central Africa: A Comparative Study between Sudan and Sweden. The Journal of Rheumatology, 40, 1777-1786.

[10] Liao, K.P., Batra, K.L., Chibnik, L., Schur, P.H. and Costenbader, K.H. (2014) Anti-CYCLIC Citrullinated peptide Revised Criteria for the Classification of Rheumatoid Arthritis. Annals of the Rheumatic Diseases, 67, 1557-1561. https://doi.org/10.1136/ard.2007.082339

[11] Combe, B. (2010) Scores to Report Diseaseactivity in Rheumatoidarthritis. Revue du Rhumatisme Monographies, 77, 17-21.

[12] Assous, N., Touzé, E., Meune, C., Kahan, A. and Allanore, Y. (2007) Cardiovascular Disease in Rheumatoid Arthritis: Single-Center Hospital-Based Cohort Study in France. Revue Du Rhumatisme, 74, 72-78.

[13] Mathieu, S., Baillet, A., Cornec, D., Fautrel, B. and Gaudin, P. (2011) Definition and Treatment of Severe Rheumatoid Arthritis in 2010: Systematic Review of the Literature. Revue Du Rhumatisme, 78, S11-S18.

[14] Roux, H. (2002) Rheumatoid Arthritis in Sub-Saharan Africa. Revue Du Rhumatisme, 69, 797-800.

[15] Bilekhot, R. and Malinga, A.C. (1998) Rheumatoid Arthritis in Congo Brazzaville. About 36 Cases. Revue Du Rhumatisme, 65, 333-337.

[16] Ntsiba, H., Biléckot, R. and Bissombolo, R. (2007) Rheumatoid Arthritis in Congo-Brazzaville. Revue Du Rhumatisme, 74, 1039-1208.

[17] Sankale, M., Sow, A.M., Diop, B., Toure, Y.L. and Ruscher, H. (1977) General Characteristics of Rheumatoid Arthritis in African Black. Le Concours Médical, 99, 1103-1112.

[18] Leleu, J.P., Dexemple, P., Soubeyrand, J. and Beda, Y.B. (1983) Adult Rheumatoid Arthritis in Tropical Africa. About 50 Observations in the Ivory Code. Revue Du Rhumatisme, 50, 195-203.

[19] Mijiyawa, M., Ekouevi, K., Adetchessi, T., Amedegnato, D.M. and Weil, B. (1994) Causes of Chronic Polyarthritis in Lomé (Togo). Revue Du Rhumatisme, 61, 29-35.

[20] Adebajo, A.O. and Reid, D.M. (1991) The Pattern of Rheumatoid Arthritis in West Africa and Comparison with a Cohort of British Patients. QJM, 292, 633-640.

[21] Jeandel, P. and Roux, H. (2002) Epidemiology of Rheumatologic Diseases in Sub-Saharan Africa. Revue Du Rhumatisme, 69, 764-776.

[22] Mijiyawa, M. (1996) Rheumatoid Arthritis in Black Africa. Revue de Médecine Interne, 17, 625-626.

[23] Zomalhèto, Z., Biaou, O., Yèkpè-Ahouansou, P., Gounongbé, M. and Avimadjè, M. (2015) Radiological Aspects of Rheumatoidarthritis in Benin. J Afr Imag Méd, 1, 39-46.

[24] Ouédraogo, D.D., Singbo, J., Diallo, O., Sawadogo, S.A., Tiéno, H. and Drabo, Y.J. (2011) Rheumatoid Arthritis in Burkina Faso: Clinical and Serological Profiles. Clinical Rheumatology, 30, 1617-1621. https://doi.org/10.1007/s10067-011-1831-1

[25] Ndongo, S., Lekpa, F.K., Ka, M.M., Ndiaye, N. and Diop, T.M. (2009) Presentation and Severity of Rheumatoid Arthritis at Diagnosis in Senegal. Rheumatology, 48, 1111-1113. https://doi.org/10.1093/rheumatology/kep178

[26] Adelowo, O.O., Ojo, O., Oduenyi, I. and Okwara, C.C. (2010) Rheumatoid Arthritis among Nigerians: The First 200 Patients from a Rheumatology Clinic. Clinical Rheumatology, 29, 593-597. https://doi.org/10.1007/s10067-009-1355-0

[27] Hodkinson, B., Musenge, E. and Tikly, M. (2015) Tight Control of Rheumatoid Arthritis in a Resource Constrained Setting: A Randomized Controlled Study Compar- 
ing the Clinical Disease Activity Index and Simplified Disease Activity Index. Rheumatology, 54, 1033-1038. https://doi.org/10.1093/rheumatology/keu443

[28] Dougados, M., Huizinga, T.W.J., Choy, E.H., Bingham III, C.O., Aassi, M. and Bernasconi, C. (2015) Evaluation of the Disease Activity Score in Twenty-Eight Joints-Based Flare Definitions in Rheumatoid Arthritis: Data from a Three-Year Clinical Trial. Arthritis Care \& Research, 67, 1762-1766. https://doi.org/10.1002/acr.22633

[29] Çalgüneri, M., Üreten, K., Akif Öztürk, M., Onat, A.M., Ertenli, I., Kiraz, S. and Akdogan, A. (2006) Extra-Articular Manifestations of Rheumatoid Arthritis: Results of a University Hospital of 526 Patients in Turkey. Clinical and Experimental Rheumatology, 24, 305-308.

[30] Minichiello, E., Semerano, L. and Boissier, M.C. (2017) Evolution over Time of Rheumatoid Arthritis: Incidence, Prevalence, Severity. Systematic Review of the Literature. Revue Du Rhumatisme, 84, 9-16.

[31] Katchamart, W., AjcharaKoolvisoot, A., EmvaleeAromdee, E., Chiowchanwesawakit, P. and Muengchan, C. (2015) Associations of Rheumatoid Factor and Anti-citrullinated Peptide Antibody with Disease Progression and Treatment Outcomes in Patients with Rheumatoid Arthritis. Rheumatology International, 35, 1693-1699. https://doi.org/10.1007/s00296-015-3271-8

[32] Richman, N.C., Yazdany, J., Graf, J., Chernitskiy, V. and Imboden, J.B. (2013) Extraarticular Manifestations of Rheumatoid Arthritis in a Multiethnic Cohort of Predominantly Hispanic and Asian Patients. Medicine, 92, 92-97. https://doi.org/10.1097/MD.0b013e318289ce01

[33] Chikanza, I.C., Stein, M., Lutalo, S. and Gibson, T. (1994) The Clinical, Serologic and Radiologic Features of Rheumatoid Arthritis in Ethnic Black Zimbabwean and British Caucasian Patients. The Journal of Rheumatology, 21, 2011-2015. 